Original Research Paper

\title{
A Passive Opportunity for Improving Air Quality in the Schools Environment: A Real-World Scale Testing
}

\author{
Pierpaoli Mattia and Fava Gabriele \\ Department of Materials, Environmental Sciences and Urban Planning - Università Politecnica delle Marche, Italy
}

\author{
Article history \\ Received: 09-02-2016 \\ Revised: 09-03-2016 \\ Accepted: 6-01-2016 \\ Corresponsding Author: \\ Pierpaoli Mattia \\ Department of Materials, \\ Environmental Sciences and \\ Urban Planning-Università \\ Politecnica delle Marche \\ Ancona, Italy \\ Email: m.pierpaoli@pm.univpm.it
}

\begin{abstract}
Can passive technology effectively enhance the indoor air quality? To improve classroom indoor air quality, an increase in ventilation and/or air purifiers are often suggested. In this study, a short-term intervention was implemented and investigated to evaluate the effects of a passive adsorbent surface on the pollutant deposition velocity and to improve the overall classroom air quality. We found that furnishing the classroom wall with adsorbent cloth surfaces results in decreased levels of indoor-generated pollutants. The main indoor parameters monitored $\left(\mathrm{CO}_{2}\right.$, relative humidity, particulate matter) in the presence of a passive sorbent material are lowered: the indoor relative humidity lower than a $7 \%$ and carbon dioxide of about $5 \%$. The $\mathrm{NO}_{2}$ deposition velocity has been estimated to $5.1 * 10^{-2}(1.8-6.0) * 10^{-2} \mathrm{~cm} / \mathrm{s}$ while for $\mathrm{SO}_{2}$ equals to $0.24(0.02$ $1.25)^{*} 10^{-2} \mathrm{~cm} / \mathrm{s}$. These results suggest that in low-polluted areas, activated carbon cloth may well be used to improve classroom indoor air quality.
\end{abstract}

Keywords: Indoor Air Quality, Classroom, Deposition Velocity, Activated Carbon Cloth, Air Cleaning

\section{Introduction}

Conventional strategies for reducing indoor air pollution are usually classified into three broad categories: Source reduction, dilution ventilation and active control systems (stand-alone air purifiers). Ventilation has high-energy expenditure related to fans and thermal conditioning. As such, reduction of pollutant emissions is generally considered the preferential strategy whenever possible (Zehra et al., 2015; Zhang, et al., 2011). However, sources associated with occupant activities, cannot be avoided and not all-indoor air pollution originates indoors. In the specific case of classroom indoor air quality, there is evidence that many schools have significant health symptoms and that improving air quality may reduce sickness and absenteeism. Some recent studies (Wichmann et al., 2010; Rivas et al., 2014) and (Anna et al., 2013) have measured the levels of several pollutants within schools, as reported in Table 1. They also highlighted the strong correlation between indoor and outdoor concentrations of certain pollutants (fine particulate matter, PM2.5 and $\mathrm{NO}_{2}$ ), to suggest that these pollutants are mainly originated from external sources.

In this study, we propose the use of a passive control strategy to remove pollutants with minimal energy penalty. As passive removal material, we selected a commercial Activated Carbon Cloth (ACC) sheets. This material is well known to have a relatively high sorption for $\mathrm{NO}_{2}$ and ozone and should produce few byproducts.

The purpose of this research is to investigate and evaluate the effects of this passive adsorbent surface to improve the overall classroom air quality.

\section{Monitoring Strategy and Locations}

The monitoring strategy adopted is based upon two different options: A continuous monitoring and a discrete sampling. Within the discrete sampling option, we evaluated the pollutant solid sorption through chemical analysis of the exposed adsorbent material, while a continuous indoor monitoring has been conducted evaluating $\mathrm{CO}_{2}$, temperature and $\mathrm{RH}$.

The research was conducted in two geographical locations and divided into two monitoring phases: A preliminary phase carried out at a primary school, in the period from January to November 2015 and a second phase at Polytechnic University of Marche in the period of October 2015-January 2016. At the primary school, named Vittorino da Feltre, located in the urban area of Piacenza (Italy), adsorbent cloths were applied in four classrooms, while at University which is located within the campus area of Ancona (Italy), only one big classroom was followed and monitored. 
Table 1. Averaged indoor concentration of selected pollutants in schools. All values are expressed in ug $\mathrm{m}^{-3}$

\begin{tabular}{|c|c|c|c|c|c|c|}
\hline \multirow{2}{*}{\multicolumn{2}{|c|}{ Compound }} & \multicolumn{4}{|c|}{ Study conducted } & \multirow[b]{2}{*}{ On site } \\
\hline & & $\mathrm{I}$ & II & III & IV & \\
\hline \multirow{9}{*}{$\mathrm{PM}_{2.5}$} & $\mathrm{NO}_{2}$ & 65.1 & 29.00 & 14.2 & & 16.9 \\
\hline & $\mathrm{SO}_{2}$ & 6.7 & & & & \\
\hline & $\mathrm{ECa}$ & & 1.30 & & 10.2 & \\
\hline & $\mathrm{OCb}$ & & 10.00 & & 22.0 & \\
\hline & $\mathrm{CO}_{3}{ }^{2-}$ & & 2.30 & & & \\
\hline & $\mathrm{SO}_{4}^{2-}$ & & 1.40 & & 2.9 & \\
\hline & $\mathrm{NO}^{3-}$ & & 0.72 & & & \\
\hline & $\mathrm{NH}^{4+}$ & & 0.48 & & 0.7 & \\
\hline & $\mathrm{Cl}$ & & & & 0.8 & \\
\hline
\end{tabular}

a. EC: Elemental carbon; b. OC: Organic carbon; I - (Zehra et al., 2015); II - (Rivas et al., 2014); III - (Wichmann et al., 2010); IV (Fromme et al., 2008)

The trial was divided into two monitoring phases: A preliminary phase was carried out at the Vittorino da Feltre primary school in Piacenza, for the period of January-November 2015 and the second phase, took place from the Polytechnic University of Marche in the period of October 2015-January 2016. The primary school is located in the urban area and in 4 classrooms were applied adsorbent panels. The university teaching room it's placed within the campus, in suburban area.

\section{Materials and Methods}

In order to carry out a monitoring of the air chemical and physical parameters and of the applied chemical adsorbent material, we have been jointly studied the two matrixes, as reported in the scheme in Fig. 1.

\section{Adsorbent Cloth Surfaces}

The Adsorbent Cloth Surfaces (ACS) adopted are formed by an activated carbon cloth tied and enclosed within two narrow hydrophobic polyester sheets forming a wafer of two materials having different physical properties.

\section{Classroom Test Experiments}

Experiments were completed in a classroom located at the University of Ancona (Italy). The room has a floor area of $90 \mathrm{~m}^{2}$ and a volume of $306 \mathrm{~m}^{3}$ with a surface to volume ratio of about $1 \mathrm{~m}^{-1}$. The classroom did not contain furniture and have vinyl wall materials and ceramic flooring. Three ACS sheets, one square meter each, were mounted on two wall of the classroom. Experiments were conducted with and without ACS adsorbent sheets during two subsequent monitoring periods.

\section{Indoor Air Monitoring}

The monitoring tool consists in a microprocessor, a memory card and sensors (Table 2). Arduino (Community, 2016) was chosen as the open-source prototyping platform. The sensors adopted to monitor air quality were: A particulate (PM10), a NDIR (NonDispersive Infrared Sensor) sensor for carbon dioxide, a Relative Humidity (RH) and temperature sensor.

Observations are recorded every $20 \mathrm{sec}$ on the logging file.

\section{Solid Adsorbent Analysis}

To estimate the deposition rate on the ACS adsorbent surface, small pre-weighted and measured ACS specimens, settled above the adsorbing surface, have been used. After the selected adsorption time, the specimens were punctually recovered, introduced in an airtight glass container with $40 \mathrm{~mL}$ of ultrapure water and mixed for $24 \mathrm{~h}$ on a suitable rotary shaker (Heidolph Reax 20), at a speed of $4 \mathrm{~min}^{-1}$. The aqueous solution was then filtered and analyzed by liquid ion chromatography (HPLC), IonPac Dionex AS23 Anion-Exchange Column. All samples were worked within three hours since their water extraction. The chemicals analyzed were organic and inorganic anions adsorbed on ACS and specifically Formiates, Acetates, Nitrates, Nitrites, Chlorides and Sulphates. It is supposed that all these compounds mimic and are related to the indoor air quality.

\section{Environmental Parameters}

A weather station close to the university has been used as reference for meteorological data.

Outdoor environmental pollutants data have been taken from two environmental monitoring stations, in Piacenza and in Ancona, operated respectively by ARPA Emilia Romagna and ARPA Marche.

\section{Data Elaboration}

$\mathrm{R}$ software environment for statistical computing was used to elaborate collected data [https://www.rproject.org/]. Psych (Revelle, 2015) and ggplot2 packages (Wickham, 2009) were used to compute data analysis and to produce graphical outputs. 


\begin{tabular}{|c|c|}
\hline $\begin{array}{l}\text { Chemical/Physical } \\
\text { Air Parameters }\end{array}$ & $\begin{array}{l}\text { Adsorbent } \\
\text { Chemical Analysis }\end{array}$ \\
\hline $\begin{array}{l}\text { Indoor air monitoring } \\
\text { Temperature } \\
\text { Relative Humidity } \\
\mathrm{CO}_{2}, \mathrm{NO}_{2}{ }^{\mathrm{a}} \\
\text { Dust } \\
\text { Outdoor air monitoring } \\
\text { Temperature } \\
\text { Relative Humidity } \\
\mathrm{NO}_{2}\end{array}$ & $\begin{array}{l}\text { ACS water extraction } \\
\text { lonic chromatography } \\
\text { Acetate } \\
\text { Chloride } \\
\text { Formiate } \\
\text { Nitrate } \\
\text { Nitrite } \\
\text { Sulphate }\end{array}$ \\
\hline
\end{tabular}

Fig. 1. Scheme of the sampling campaign for the joint monitoring of the two compartments; a. $\mathrm{NO}_{2}$ indoor air levels were not continuously monitored, grab samples were analyzed occasionally

Table 2. Sensor used in the monitoring campaign

\begin{tabular}{ll}
\hline Parameter & Sensor \\
\hline Dust & Sharp GP2Y1010 \\
$\mathrm{CO}_{2}$ & $\mathrm{~K}-30 \mathrm{CO}_{2}$ sensor \\
Temperature, Relative Humidity & DHT 22 \\
Multi-purpose air quality gas & MQ135 gas sensing \\
\hline
\end{tabular}

\section{Chemical-Physical Parameters}

Physical parameters dataset was divided in two parts: One related to the classroom occupancy and the other, complementary, showing the environmental conditions in the absence of occupants. The outdoor temperature decreased by $5^{\circ} \mathrm{C}$ during the entire observed period, while the outdoor relative humidity remained high and constant. The particulate sensor has been found correlated with the relative humidity and thus not further considered, instead $\mathrm{CO}_{2}$ sensor appears more faithful. The indoor to outdoor averaged ratio appears increased because of the winter season, but the classroom maximum values are attenuated, as well pointed out by the characteristics spikes observed during the occupancy hours in the classroom.

\section{Results}

The complete data set monitored at Marche Polytechnic University from October to December 2015 is summarized on Fig. 2. The graphs show $15 \mathrm{~min}$ averaged values of indoor and outdoor temperature, relative humidity, carbon dioxide concentration and the raw signal from the particulate sensor. It is possible to distinguish two different period: The first, plotted in red, has been used as reference and the second, in blue, in which ACS where applied.

\section{Chemical-Physical Parameters}

The complete physical and chemical dataset registered is composed by observations reported in Fig. 2. For the sake of clarity, it was split in two parts: Ones related to the classroom occupancy and the other, complementary, showing the indoor state in the absence of students.

To highlight average values and distributions, data monitored during room occupation were selected. Graphs that are more relevant are shown on Fig. 3. As it can be observed, excluding the outdoor relative humidity, all the other parameters appear lower during the second period, after ASC placing.

Relative humidity, considered an indicator of indoor air quality, was monitored throughout the day when changes in occupancy affect the rate at which water vapour is generated. Outdoor relative humidity remained constant, while indoor reduced after the presence of ASC together with PM10 levels. Anyway, aerosol trend strongly correlated with the relative humidity, seriously questioning the meaning of the decrease observed.
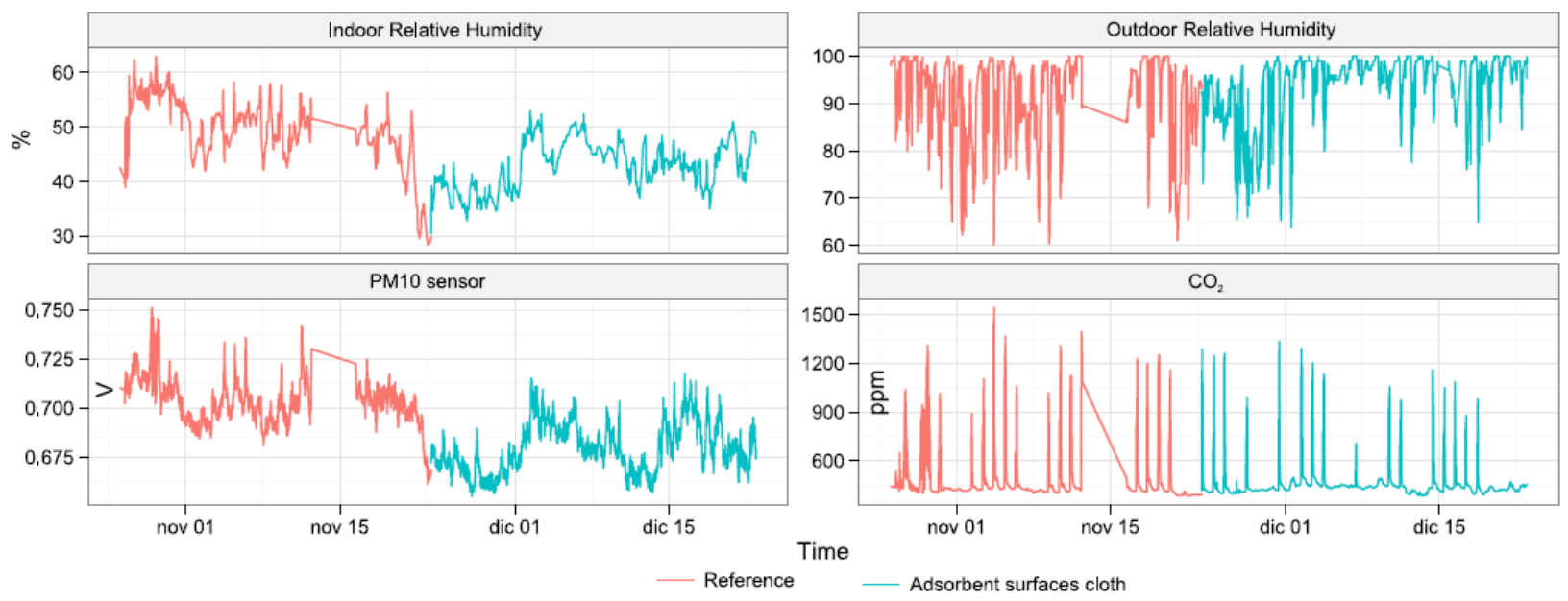

Fig. 2. Time series plots of different parameters continuously monitored 

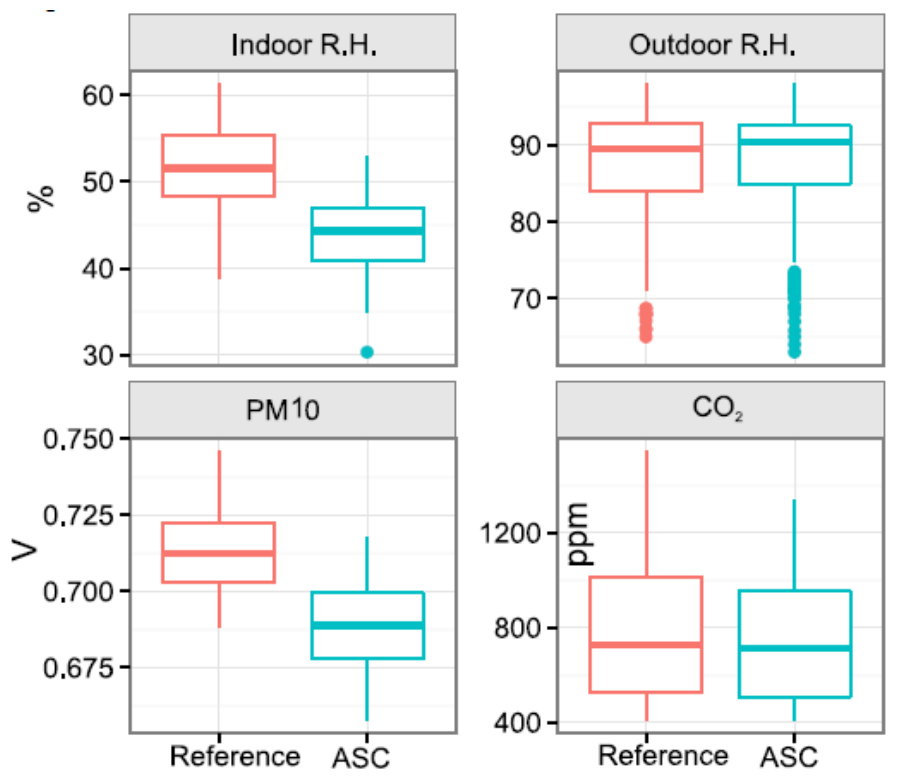

Fig. 3. Boxplot of monitored variables, in presence and absence of panels

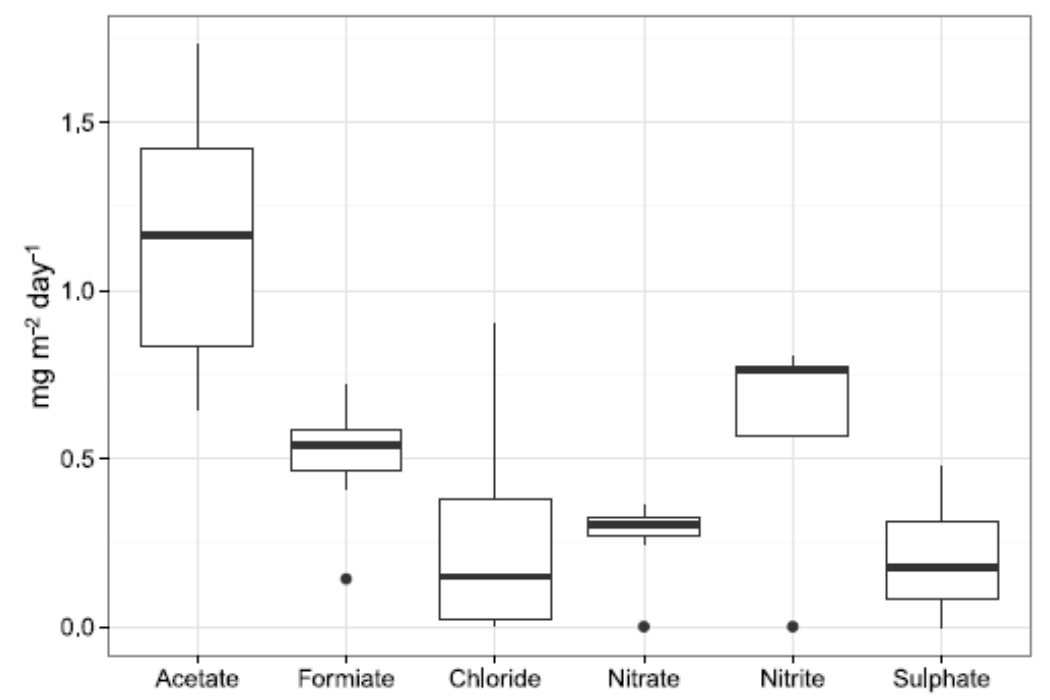

Fig. 4. Accumulation rate of the anions on the activated carbon sample expressed by $\mathrm{mg} \mathrm{m}^{-2}$ day $^{-1}$

Table 3. Accumulation of anion on the activated carbon sample. Values are expressed as median $\left(1^{\circ}\right.$ quartile $-3^{\circ}$ quartile $)$ in $\mathrm{mg} / \mathrm{m}^{2}$ Days

\begin{tabular}{llllr} 
& & & 10 & 21 \\
Anion & 0 & $70.4(62.5-71)$ & $67.7(63.7-68.6)$ & 31 \\
\hline Acetate & $9.5(0.1-19.2)$ & $6.7(6.7-6.9)$ & $11.3(4.8-11.5)$ & 90.4 \\
Formiate & $1.4(0.4-2.6)$ & $153(158-157)$ & $158.2(158-160)$ & 12.8 \\
Chloride & $171(157-185)$ & $3.6(7.5-3.6)$ & $6.1(1.7-6.3)$ & 185.0 \\
Nitrate & $2.2(0-4.4)$ & $6.0(9.7-6.0)$ & $22.3(10.1-22.6)$ & 7.7 \\
Nitrite & $1.1(0.5-1.7)$ & $134(138-137)$ & $144(141-145)$ & 23.5 \\
Sulphate & $147(135-186)$ & & & 154.0 \\
\hline
\end{tabular}

Carbon dioxide also is useful as an indicator of general air quality in buildings where there are significant metabolic sources. This $\mathrm{CO}_{2}$ sensor showed characteristics spikes during the occupancy of the classroom. While the average concentration appear mostly unchanged, maximal values are 
attenuated. For instance, the $\mathrm{CO}_{2}$ level is $5 \%$ lower in the presence of the ACS.

As a distinct way to evaluate the ACS effect, $\mathrm{CO}_{2}$ decreasing rate afterschool has been tested. With a classroom constant mechanical ventilation, an air change rate estimation (AER) was conducted, following a decay method. When there is no source, i.e., $S=0$, AER can be resolved from the Equation 1:

$C=\frac{Q \cdot C_{i n}}{A E R \cdot V}\left(1-e^{-A E R \cdot t}\right)+C_{0} e^{-A E R \cdot t}$

Where:

$C=$ The concentration which varies in time $\left[\mathrm{mg} / \mathrm{m}^{3}\right]$

$Q \cdot C_{i n}=$ The pollutant inflow $[\mathrm{mg} / \mathrm{min}]$

$C_{0}=$ The initial pollutant concentration

$V=$ The room volume $\left[\mathrm{m}^{3}\right]$

$A E R=$ The air change rate estimation $\left[\mathrm{min}^{-1}\right]$

Monitored data has been fitted and AER, has been determined.

A number of AER evaluated gave an average value equal to 1.85 (1.71-1.91) $\mathrm{h}^{-1}$, compared to 1.99 (1.912.05) $\mathrm{h}^{-1}$ in the presence of ACS. In the presence of ACS, AER results $7 \%$ higher than in the absence.

\section{Accumulation on Activated Carbon}

Table 3 shows the amount of anions adsorbed on the activated carbon samples, extracted, analyzed and normalized on the area of the sample itself. Values are expressed in $\mathrm{mg} / \mathrm{m}^{2}$.

Subtracting the initial contenent at $t=0$, as the background value, it was obtained the accumulation rate. Figure 4 shows statistics of the obtained values.

\section{Nitrogen Dioxide Deposition Velocity}

Recently, experimental evidence has shown that chemical reactions between ozone and/or nitrogen dioxide $\left(\mathrm{NO}_{2}\right)$ and organic compounds produce eye and airway irritating species (Yooa et al., 2015; Lee et al., 2002). However, these are not easily characterized by conventional sampling and analytical techniques. These chemical reactions can occur indoors and there is indirect evidence that they can be absorbed by chemical reactive materials (Haghighat et al. 2008; Son et al., 2011). Indoor $\mathrm{NO}_{2}$ is generated from various sources, including indoor combustion, tobacco smoking and infiltration from outdoors. The 24-h averages of $\mathrm{NO}_{2}$ are reported between 8-209 ppb depending on environmental factors such as the ventilation rate, but peak concentrations can reach 955 ppb and be even more problematic because of this high levels can persist for longer times than in outdoor air. For this reason, we assume that this pollutant fate can be taken as a useful index for passive sink of indoor pollutants.

Gaseous $\mathrm{NO}_{2}$, adsorbed on solid activated carbon may transform into adsorbed forms of nitrogen, namely nitrites $\left(\mathrm{NO}_{2}^{-}\right)$and nitrates $\left(\mathrm{NO}_{3}{ }^{-}\right)$or react with adsorbed VOC or aldehydes. Measuring the accumulation on the activated carbon and using the $\mathrm{NO}_{2}$ reported in Table 2, makes it possible determining its deposition velocity on the ACS.

According the previous work (Fava and Ruello, 2006), the time derivative of the accumulation rate can be expressed as the product of the measured air concentration of a certain compound $\left(C_{\text {air }}\right)$ with the correspondent deposition velocity $\left(v_{d e p}\right)$ (Equation 2$)$ :

$\frac{1}{A} \frac{d m_{r e m}}{d t}=C_{a i r} \cdot V_{d e p}(t)$

The left term is obtained by dividing the values of anion accumulated on the activated carbon,found in Table 3, on the days exposed. By re-arranging Equation $2, v_{\text {dep }}$ is obtained.

During the first month of the ACS application in the Ancona classroom, $\mathrm{NO}_{2}$ deposition velocity median value has been estimated as $5.1 * 10^{-2}(1.8-6.0) * 10^{-2} \mathrm{~cm} / \mathrm{s}$ by using Equation 2 and taking into account either nitrites and nitrates. Similarly, $\mathrm{SO}_{2}$ deposition velocity has been estimated by accounting analyzed sulphates and the average $\mathrm{SO}_{2}$ concentration recorded by a local environmental monitoring station.

These velocities are comparable with the ones detected in a previous work (Fava and Ruello, 2006). Instead, considering the results obtained in the primary school in Piacenza, an halved adsorptive capacity is observed after one year of exposition which indicates an aging effect on the ACS.

\section{Discussion}

\section{Correlation Plot}

Figure 5 shows the correlation between the concentrations of ions from the carbon extraction with water. Values reported are Pearson's product moment correlation coefficient. Crossed values are considered not to be significant (significance level threshold is equal to 0.05 ).

It is possible to notice 3 strong correlations among phosphate and sulphate, chlorides and phosphates. Also nitrate with acetate and formiate are correlated. Weak correlations were found between the acetate and chloride and the fluoride with the chloride, probably because of its low presence in the atmosphere. The majority of the correlations have been rejected because of the significance level equal to 0.05 . 


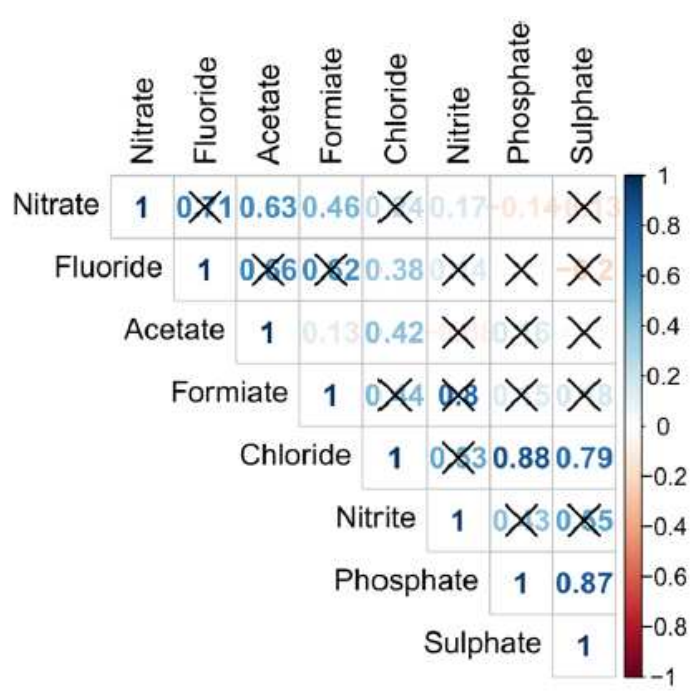

Fig. 5. Correlation matrix of the anion extracted from the activated carbon

\section{Comparison of the Accumulation Rate}

It is of worth noting that nitrate and sulphate accumulation rate for both the classrooms experimented are initially comparable, while for the longer periods monitored in the primary school, a decreasing rate is observed. This may be attributed to the exhaustion of the adsorbing capacity of ACS, or to a depleted ability induced by a water vapor adsorbed, as monitored by the decrease of the relative humidity in the room.

\section{Conclusion}

The aim for this research was to study the effect of adsorbent passive materials posted within classrooms, in terms of air quality improvement. The effect of passive adsorption have been discussed as indoor air improvement, or as pollutants removal.

The implemented monitoring strategy adopted, makes it possible to record continuously the classroom $\mathrm{RH}$ and $\mathrm{CO}_{2}$ levels and weekly grabbing samples of ACS for analyzing their accumulated pollutants content during the testing. Monitoring by automatic devices revealed unsuitable for evaluating any possible adsorption effect. The actual real-scale conditions makes difficult any environmental comparison, anyway it may be noted that $\mathrm{RH}$ and $\mathrm{CO}_{2}$ levels in the classroom appear lowered after the ACS insertion (R.H. 7\%, $\mathrm{CO}_{2} 5 \%$ ).

By dividing the anion accumulation on the activated carbon by the time, accumulation rate have been obtained. It has been shown that there is a gradual accretion on the ACS and that the accumulation rate differs for the various anions, which tends to decrease, halving after about 5-6 months. Essentially, during the first month, acetate, chloride, formiate, nitrate, nitrite and sulphate accumulation rate, respectively equal to 1.16 (0.69-1.43), 0.42 (0.05-0.9), 0.41 (0.04-0.55), 0.31 $(0.3-0.34), 0.24(0.02-1.25) \mathrm{mg} / \mathrm{m}^{2}$ day.

The $\mathrm{NO}_{2}$ deposition velocity over the activated carbon cloths, for the first month of application, has been estimated to $5.1 * 10^{-2}(1.8-6.0)^{*} 10^{-2} \mathrm{~cm} / \mathrm{s}$. The $\mathrm{SO}_{2}$ deposition velocity similarly, for the $\mathrm{SO}_{2}$, the deposition velocity equals to $0.24(0.02-1.25)^{*} 10^{-2} \mathrm{~cm} / \mathrm{s}$.

Further studies, including the eventual effect on indoor bio-aerosols, are encouraged to understand the passive adsorption configuration adopted. Additional testing work is necessary to provide accurate predictions of the time-dependent de-polluting effect and how it is influenced by the relative humidity, as well as air composition and exposure history.

\section{Acknowledgement}

Acknowledgement of this work in intended to the Anemotech srl company for providing the material used in this study and to Mr. Cammi Gianmarco for his efforts in organizing the real scale study.

\section{Funding Information}

This research was funded jointly with the Ecoprogram Srl financial support.

\section{Author's Contributions}

Mattia Pierpaoli: Responsible for the data collection and analysis, he realized the Arduino-based monitoring tool.

Gabriele Fava: Organized the study provided model expertise and coordinated the research.

\section{Ethics}

This article is original and contains unpublished material. No ethical issues are involved.

\section{References}

Anna, Z., I. Sówka, B. Krupińska, J. Zwoździak and A. Nych et al., 2013. Infiltration or indoor sources as determinants of the elemental composition of particulate matter inside a school in Wrocław, Poland? Build. Environ., 66: 173-180. DOI: 10.1016/j.buildenv.2013.04.023

Community, A., 2016. Air quality in Europe-2015 report. E.E.A.

Fava, G. and M.L. Ruello, 2006. Riduzione di precursori gassosi di aerosoli tramite pannelli adsorbenti fissi. Un esempio di applicazione in area urbana. 
Fromme, H., J. Diemer, S. Dietrich, J. Cyrys and J. Heinrich et al., 2008. Chemical and morphological properties of particulate matter $\left(\mathrm{PM}_{10}, \mathrm{PM}_{2.5}\right)$ in school classrooms and outdoor air. Atmospheric Environ., 42: 6597-6605. DOI: 10.1016/j.atmosenv.2008.04.047

Haghighat, F., C.S. Lee, B. Pant, G. Bolourani and N. Lakdawala et al., 2008. Evaluation of various activated carbons for air cleaning-towards design of immune and sustainable buildings. Atmos. Environ., 42: 8176-8184.

DOI: 10.1016/j.atmosenv.2008.07.061

Lee, K., J. Xue, A.S. Geyh, H. Ozkaynak and B.P. Leaderer et al., 2002. Nitrous acid, nitrogen dioxide and ozone concentrations in residential environments. Environ. Health Perspect., 110: 145-149. PMID: 11836142

Revelle, W., 2015. Psych: Procedures for Psychological, Psychometric and Personality Research.

Rivas, I., M. Viana, T. Moreno, M. Pandolfi and F. Amato et al., 2014. Child exposure to indoor and outdoor air pollutants in schools in Barcelona, Spain. Environ. Int., 69: 200-212. DOI: 10.1016/j.envint.2014.04.009

Son, Y.S., Y.H. Kang, S.G. Chung, H.J. Park and J.C. Kim, 2011. Efficiency evaluation of adsorbents for the removal of $\mathrm{VOC}$ and $\mathrm{NO} 2$ in an underground subway station. Asian J. Atmos. Environ., 5: 113-120. DOI: 10.5572/ajae.2011.5.2.113
Wichmann, J., T. Lind, M.M. Nilsson and T. Bellander, 2010. $\mathrm{PM}_{2.5}$, Soot and $\mathrm{NO}_{2}$ indoor-outdoor relationships at homes, pre-schools and schools in Stockholm, Sweden. Atmospheric Environ., 44: 4536-4544. DOI: 10.1016/j.atmosenv.2010.08.023

Wickham, H., 2009. Ggplot2: Elegant Graphics for Data Analysis. 1st Edn., Springer-Verlag, New York, ISBN-10: 0387981411, pp: 213.

Yooa, J.Y., C.J. Park, K.Y. Kim, Y.S. Son and C.M. Kang et al., 2015. Development of an activated carbon filter to remove $\mathrm{NO}_{2}$ and $\mathrm{HONO}$ in indoor air. J. Hazardous Mater., 289: 184-189. DOI: $10.1016 /$ j.jhazmat.2015.02.038

Zehra, B., G. Doğan, D. Arslanbaş, B. Pekey and H. Pekey et al., 2015. Determination of the personal, indoor and outdoor exposure levels of inorganic gaseous pollutants in different microenvironments in an industrial city. Environ. Monitor. Assess., 187: 590-590. DOI: 10.1007/s10661-015-4816-8

Zhang, Y., J. Mo, Y. Li, J. Sundell and P. Wargocki et al., 2011 Can commonly-used fan-driven air cleaning technologies improve indoor air quality? A literature review, Atmos. Environ. 45: 4329-4343. DOI: 10.1016/j.atmosenv.2011.05.041 